\title{
Effects of low radioactivity of the Yemeni's Catha edulis (Khat) and tobacco plants
}

\author{
Muhammad Ahamad AL-Jalali \\ Physics Department, Faculty of Science, Taif University, 21974 Taif, P. O. Box 888, kingdom of Saudi Arabia. \\ (Author was a lecturer at the University of Sana'a, Yemen, in the period from 1997 to 2003.) \\ E-mail: aljalaliphys@gmail.com
}

Copyright $\odot 2014$ Muhammad Ahamad AL-Jalali. This is an open access article distributed under the Creative Commons Attribution License, which permits unrestricted use, distribution, and reproduction in any medium, provided the original work is properly cited.

\begin{abstract}
The present work aims to shed light on the relationship between the cause of cancer and low radioactivity distribution of Catha edulis (Khat) and tobacco grown in Yemen, whereas they have a remarkable relationship with human health, due chewing of Catha edulis and smoking tobacco simultaneously. The complicated behavior of smoking tobacco and chewing Catha edulis at the same time could be responsible for different kinds of cancer diseases. Wavelength Dispersive X-ray Fluorescence (WDXRF) spectrometer was used to specify the chemical composition of Catha edulis and tobacco plants. In addition, radioactive detectors reveal the distribution of the radioactivity of Catha edulis and Tobacco plants is higher than the natural radioactivity distribution, because of the presence of the heavy minerals and different radioisotopes in Catha edulis and Tobacco plants.
\end{abstract}

Keywords: Low Radioactivity, Catha Edulis, Tobacco, WDXRF, Oral and Lung Cancers.

\section{Introduction}

The organic and inorganic Tobacco's tar and Catha edulis chewing are not only which kill, but also the expected radiation coming out of these plants is responsible for killing by different kinds of cancer diseases.

Catha edulis and Tobacco are the silent killers of Yemen, because they have, all an important triggering factor in cancers of the mouth, lung, and other diseases [1], [2]. A huge number of Yemeni men and women (about 20,000) suffer from cancer every year, Figure (1) [3], [4].

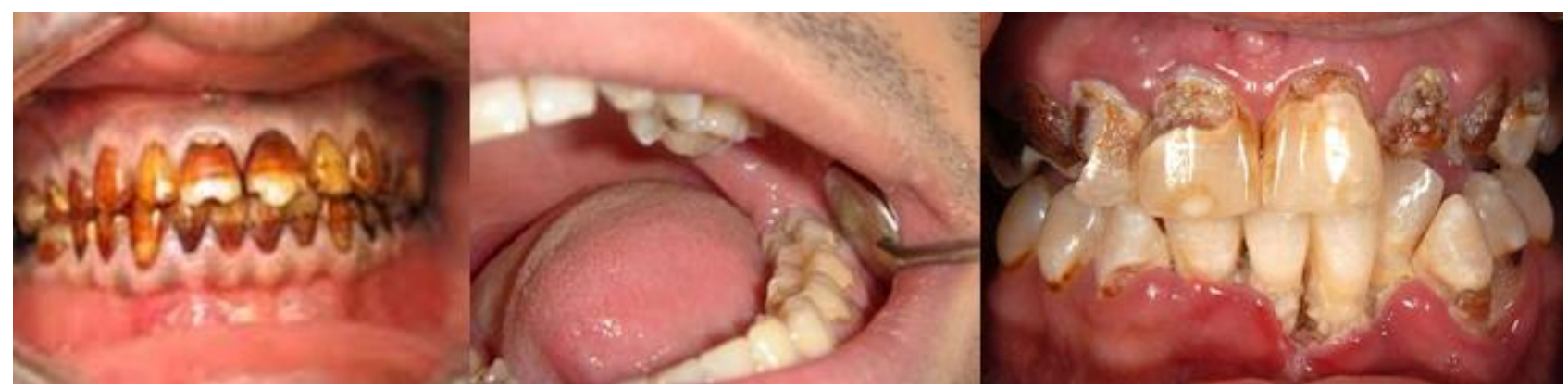

Fig. 1: Some Types of Oral Cancer Due To the Use of Khat and Tobacco.

Every day, most of Yemeni people relax for Catha edulis chewing session. They also at the same session smoke cigarette and Tobacco in a hookah (waterpipe) [5], [6].

The Catha edulis tree is popular with people looking for the drug-like effect, chewing their leaves generates intense thirst, produces excitement with deportation sleep, and enhances communication between people. It has a devastating effect on people's health because it contains cathinone, and an amphetamine-like stimulant [7], [8], [9]. Catha edulis has classified as a mild drug and not dangerous addictive since 1980 [10]. 
Whereas Tobacco is a leafy green plant, used as a cigarette, pipe, cigar, or Tobacco in a hookah. The burning of Tobacco generates approximately 4000 chemical compounds [11], and it contains the Tar and nicotine, which is a polycyclic aromatic hydrocarbon and classified as a drug and addictive compounds [12], [13].

It notes that, both Catha edulis and Tobacco contain many common radioactive elements, and the most dangerous state in Yemeni society that they usually use Catha edulis and Tobacco every day for a long time, Figure (2).

In the present work, the seriousness of this situation in the long term has been demonstrated.

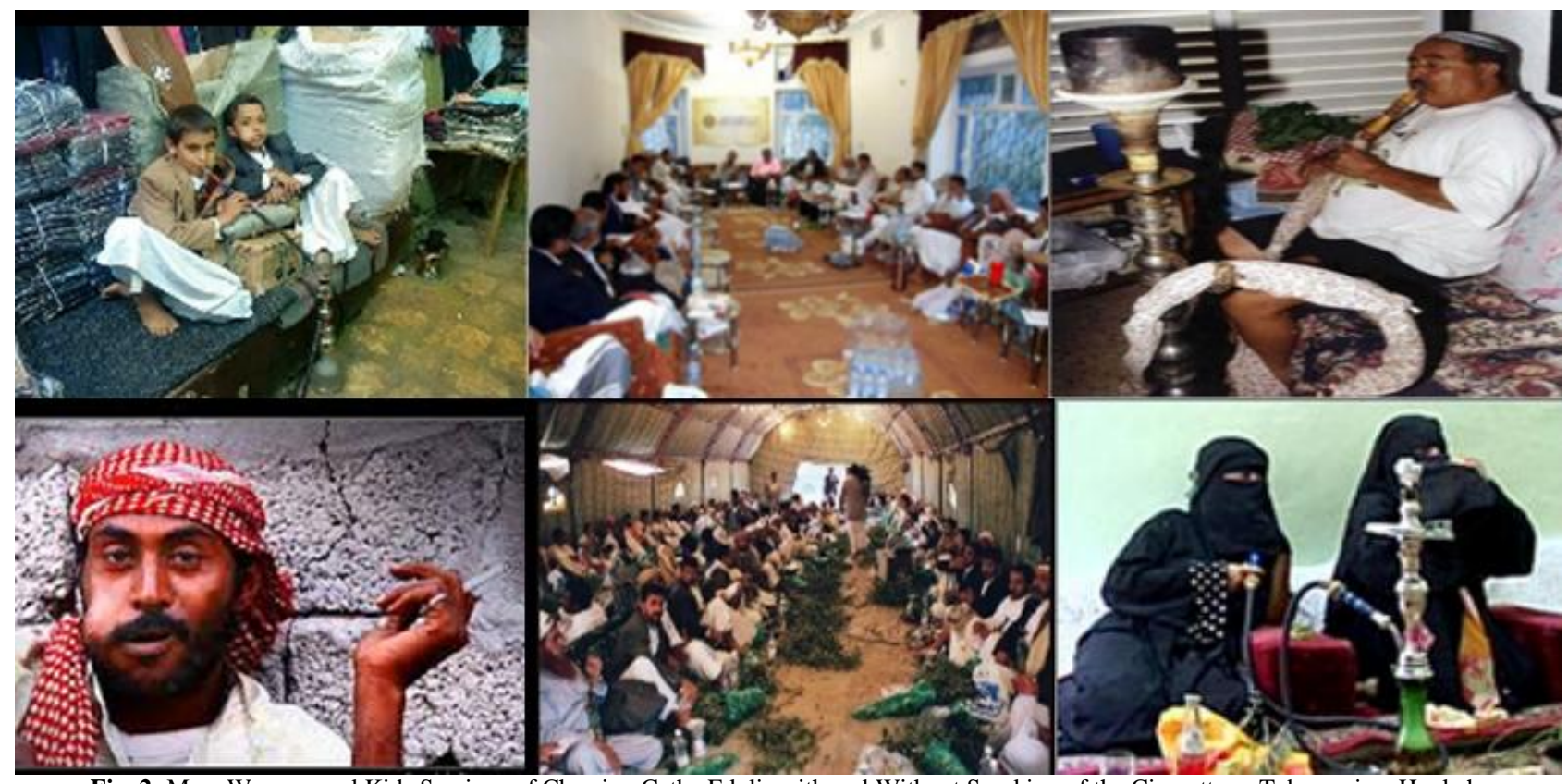

Fig. 2: Men, Women, and Kids Sessions of Chewing Catha Edulis with and Without Smoking of the Cigarette or Tobacco in a Hookah.

\section{Materials and methods}

\subsection{Radioactive instrument}

Detector of nuclear radiations was used to study the radioactivity of the Catha edulis, and Tobacco plants. The results were compared with natural radioactivity, So that, at the same time two counters had been used; the first counter to measure Catha edulis and Tobacco radioactivity separately, while the other counter to measure the environmental radioactivity. The numeric data dealt with suite statistical analysis software program, and $\mathrm{\gamma}$-spectroscopy was used in part two [32].

\subsection{Wavelength dispersive $x$-ray fluorescence spectrometry}

High performance sequential WDXRF spectrometer (Axios 2005, PANalytical, Netherlands) was used in Egypt for quantitative analysis of river Nile sediments and for the same purpose for the Catha edulis plant samples. The WDXRF allowed rapid and accurate elemental analysis technique and was able to deal with the different type of samples in the form of solids, fused beads, pressed or loose powder and liquid samples. To recognize all the elements in the present plant samples, the characteristic radiation of the major, minor and trace elements were recorded in ten different scans [32]. Each scan covers a certain number of the expected elements and the peak areas of the characteristic radiation were estimated. Using the measured intensities of the characteristic radiation, a standard-less analysis program (IQ+ software) which depended on fundamental parameters was used in the present work [14], [15].

\subsection{Samples}

Different kinds of Catha edulis and Tobacco (leaves and stalks) were collected, and were not exposed to any kind of pesticides or toxins; Fresh bundles of them were obtained from Hajjah and Dhamar cities in Yemen. Figure (3) illustrates Catha edulis and Tobacco fields in Yemen. The collected plant samples washed and dried, because washing removes accumulated materials that can contribute to isotopes. Afterward, the samples subjected to many experiments in order to discover the radioactivity and mineral elements involved in their composition. 


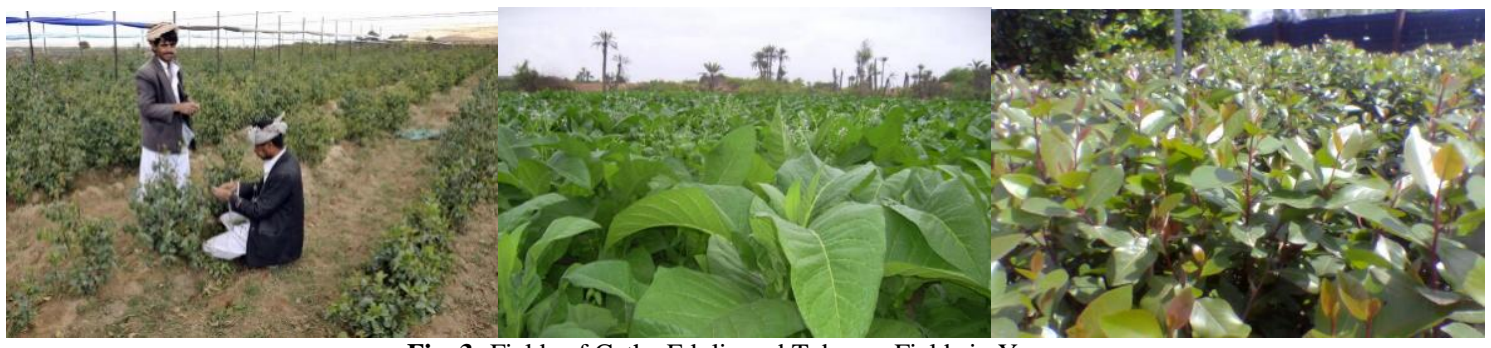

Fig. 3: Fields of Catha Edulis and Tobacco Fields in Yemen

\section{Results and discussion}

Radioactivity in Catha edulis was never discussed in the literature before. Figure (4) illustrates the Characteristic (Gaussian) curves for natural radiations (environmental radioactivity) and radioactivity of Catha edulis and tobacco leaves (two kinds of Tobacco leaves were used the second type is named Surratt in this city).

It would be mentioned that, the distribution of the radioactivity of Catha edulis and Tobacco plants is higher than the natural radioactivity distribution.

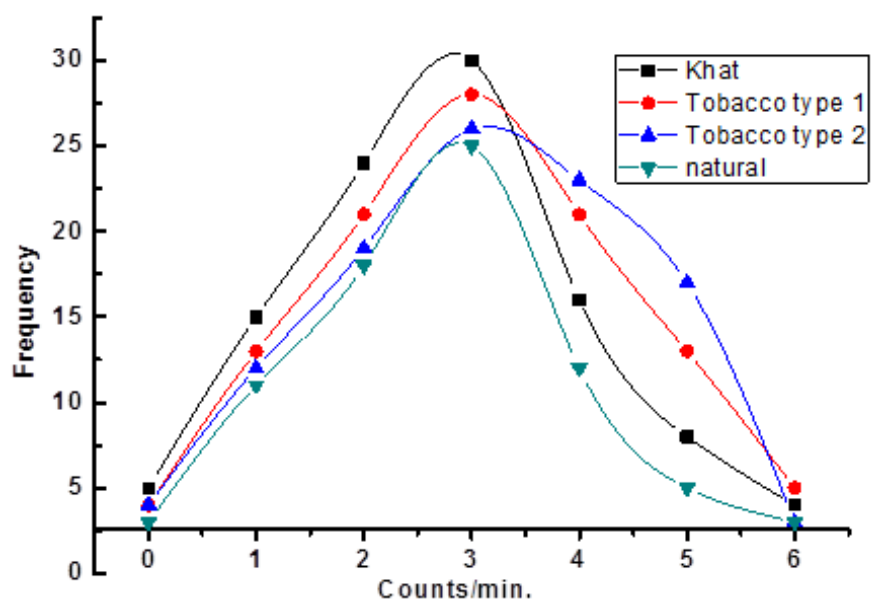

Fig. 4: Characteristic Curves for Natural radioactivity and Radioactivity of the Khat and Tobacco Plants

Figure (4), shows the presence of low radioactivity, which has a serious effect on living cells, and the severity and risk of radiation on users of Tobacco and Catha edulis will appear in the long term.

Analytical methods of the Yemeni's Catha edulis (far from organic constituents) allow the determination of 22 elements (Al, Ba, Bi, Br, Ca, Cl, Cu, Fe, K, Mg, Mn, Na, Ni, P, Rb, S, Si, Sr, Ti, Y, Zn, Zr.).

Thermal analysis techniques and Wavelength Dispersive X-Ray Fluorescence (WDXRF) was used for estimation of the inorganic constitutes of Catha edulis plants, where the characteristic radiation of $(\mathrm{Cu}, \mathrm{Ni}, \mathrm{Fe}$, and $\mathrm{Mn})$ and $\mathrm{Rb}, \mathrm{Sr}$ and other's elements were recognized. Complete details of the quantitative analysis using X-ray fluorescence can be found in ref. [14], [15], [16]. Figures $(5,6)$ show arbitrary sum of some scans [32] of the initial characteristic radiation of Catha edulis analysis to ensure only the existence of those 22 elements.

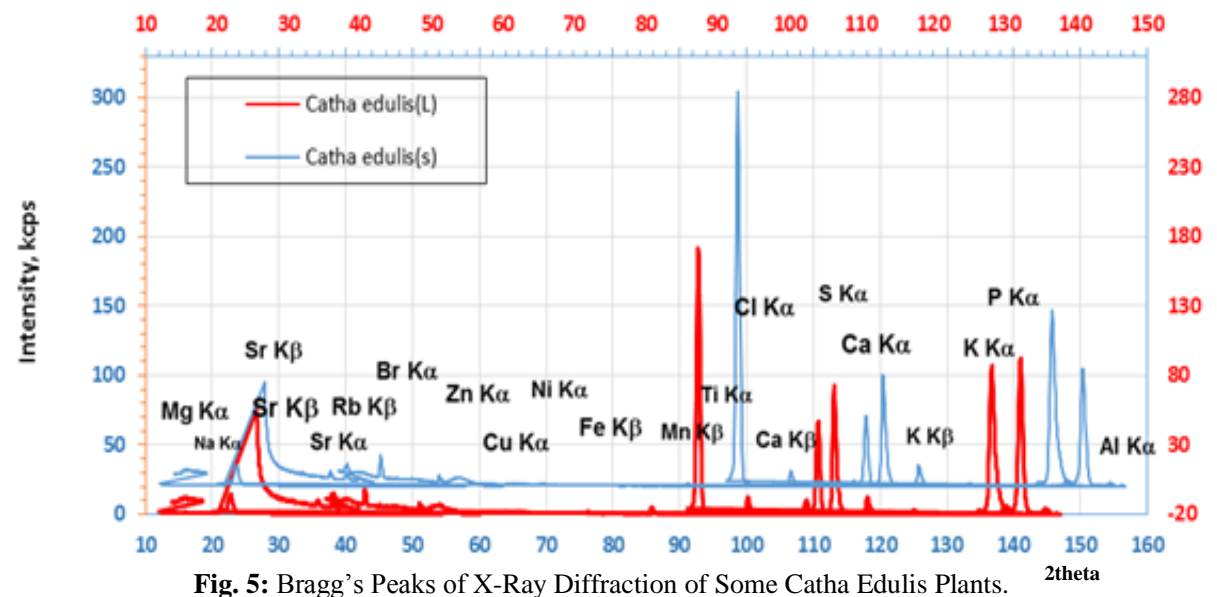




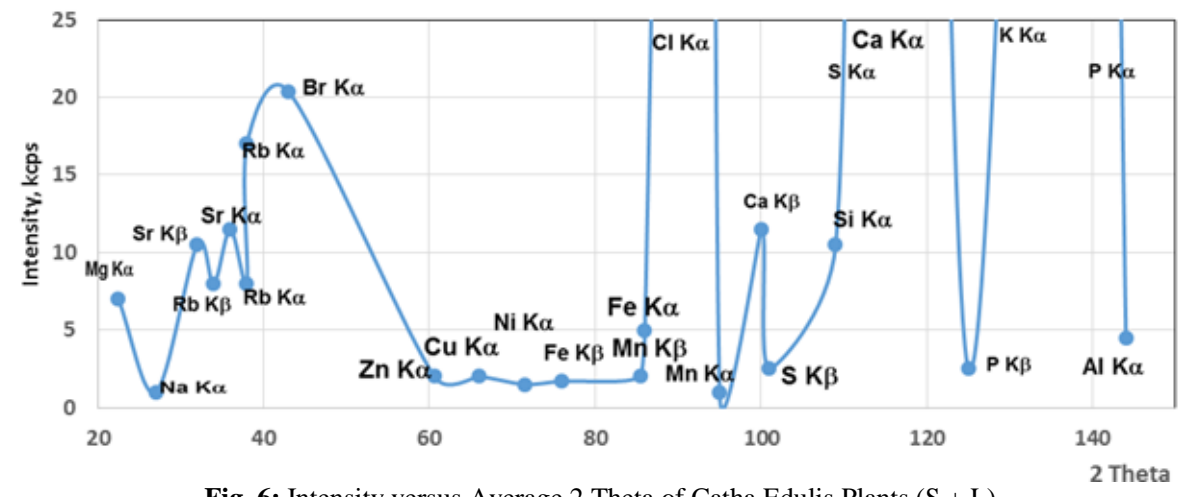

Fig. 6: Intensity versus Average 2 Theta of Catha Edulis Plants (S + L)

As for Tobacco, more than 50 elements were discovered by WDXRF analysis [17]. Where some of them are (Al, As, $\mathrm{Ba}, \mathrm{Be}, \mathrm{B}, \mathrm{Cs}, \mathrm{Cl}, \mathrm{Cr}, \mathrm{Co}, \mathrm{Cu}, \mathrm{F}, \mathrm{Au}, \mathrm{I}, \mathrm{Fe}, \mathrm{Pb}, \mathrm{Li}, \mathrm{Mg}, \mathrm{Mn}, \mathrm{Hg}, \mathrm{Mo}, \mathrm{Ni}, \mathrm{P}$ t, Po-210, Ra-226, Rb, Se, Si, Ag, Na, Sr, S, Ti, Sn, T, U, V, Zn, BI, Cd, Cr, Co, Cu, Pb, Mn, Hg, Ni, Tl, tin, Zn, K, , Ca, Sb). In addition, other methods can be found in references [18], [19], and [20].

Studying indicates that metals such as (As, $\mathrm{Cr}, \mathrm{Zn}, \mathrm{Fe}$ ) can quickly become toxic. Whereas $(\mathrm{Cd}, \mathrm{Cu}, \mathrm{Pb}, \mathrm{Cr}, \mathrm{Zn}, \mathrm{Hg}$ ) are heavy metals, and ${ }^{226} \mathrm{Ra},{ }^{214} \mathrm{Bi},\left({ }^{238} \mathrm{U}\right.$ series $),{ }^{228} \mathrm{Ac},{ }^{228} \mathrm{Ra}\left({ }^{232} \mathrm{Th}\right.$ series $),{ }^{40} \mathrm{~K},{ }^{137} \mathrm{Cs},{ }^{210} \mathrm{Po}$, are very dangerous radioactive metals. Those heavy and radioactive elements increase the intake radiation dose, which means that there are probabilities of detection of many diseases, especially oral and lung cancer [21], [22], [23], [24], [25], [26].

A strange result could be found in Figure (3) that the radioactivity of Catha edulis is greater than the radioactivity of tobacco; although the elemental analysis indicates that the radioactive elements in Tobacco much more than in Catha edulis, these reflect that we need more study of this complex subject.

At the end, smoking of Tobacco and Catha edulis chewing simultaneously will double the effect of low radiation dose and create conditions that cause an oral and lung cancer in the long term [27], [28], [29], [30], [31].

\section{Conclusion}

Experimental results of WDXRF and low radioactivity on Khat and tobacco plants discovered many radioactive materials and the most dangerous heavy metals were quantitatively determined, where those radioactive materials will increase the intake radiation dose in the human body, and can cause oral and lung cancer.

So that, Radiology Physics sources indicate the existence of two types of diseases arising from low radioactivity:

1. The first type makes a change in the composition of genes and produces genetic mutations in living cells called genetic effects, which pass to the offspring.

2. The second kind makes somatic effects where cancer is the primary result, it might sometimes call the carcinogenic effects, so that living cells multiplied with unfamiliar and unnatural states and its bad results could observe after many years.

Finally, this issue, if it does not immediately treating by health organizations, especially the World Health Organization (WHO), Cancers will increase in the majority of Yemeni society and will spread faster than of what be expected.

\section{Acknowledgement}

I am greatly indebted to Dr. AbdallahA. Shaltout (Spectroscopy Department, Physics Division, National Research Center, Egypt and Physics Department, Taif University, Saudi Arabia.), Who provided me with quantitative analysis results to Yemeni's Catha edulis samples by private communications, and all those whom I relied on their publications.

\section{References}

[1] Abdul-Hamid G, Saeed N M, Al-Kahiry W, Shukry S, "Pattern of head and neck cancer in Yemen," Gulf J Oncolog. 7, (2010), 21-24. PMID: 20164005.

[2] Al-Hadrani A M, "Khat induced hemorrhoidal disease in Yemen," Saudi Med J. 21 (5), (2000) 475-477. PMID:11500685

[3] Nasr A H, Khatri M L,"Head and neck squamous cell carcinoma in Hajjah, Yemen," Saudi Med J. 21 (6), (2000), 565-568. PMID: 11500708.

[4] Soufi H E, Kameswaran M, Malatani T, "Khat and oral cancer," The Journal of Laryngology \& Otology 105 (8), (1991), 643-645. DOI: http://dx.doi.org/10.1017/S0022215100116913

[5] Luqman W, Danowski T S, "The use of khat (Catha edulis) in Yemen. Social and medical observations, " Ann Intern Med. 85 (2), (1976), 246249. PMID:942147

[6] Al-Motarreb A, Baker K, Broadley K J, " Khat: pharmacological and medical aspects and its social use in Yemen,"Phytother Res. 16 (5), (2002), 403-413. PMID:12203257

[7] Al-Motarreb A, Baker K, Broadley K J, "Khat: Pharmacological and Medical Aspects and its Social Use in Yemen,"Phytother. Res. 16, (2002), 403-414. DOI: 10.1002/ptr.1106 
[8] Kalix P, "Pharmacological properties of the stimulant Catha edulis", Pharmacology\& therapeutics 48, (1990), 397-416. DOI: none

[9] Kennedy J G, Teague J, Rokaw W, Cooney E,"A medical evaluation of the use of qat in North Yemen, "Social Science \& Medicine 17(12), (1983), 783-793. http://dx.doi.org/10.1016/0277-9536(83)90029-1

[10] Nutt D, King LA, Blakemore C,"Development of a rational scale to assess the harm of drugs of potential misuse", Lancet 369(9566), (2007), 1047-53. DOI:10.1016/S0140-6736(07)60464-4

[11] $15^{\text {th }}$ World Conference on Tobacco or Health (WCTOH), 20 to 24 March 2012, Singapore (2012).

[12] Halboub E, Dhaifullah E, Abdulhuq M, "Catha edulis chewing and smoking effect on oral mucosa: a clinical study",ActaMedica (Hradec Kralove) 52(4), (2009) ,155-8. PMID:20369709

[13] Al-Zubairi A, Al-Habori M, Al-Geiry A,"Effect of Catha edulis (Catha edulis ) chewing on plasma lipid peroxidation", J Ethnopharmacol87(1), (2003), 3-9. PMID:12787947

[14] ShaltoutA A, MoharramM A, Mostafa N Y, "Wavelength dispersive X-ray fluorescence analysis using fundamental parameter approach of Catha edulis and other related plant samples", Spectrochimica Acta Part B: Atomic Spectroscopy67, (2012), 74-78. http://dx.doi.org/10.1016/j.sab.2012.01.004.

[15] Shaltout A A, Allam M A, Moharram M A, " FTIR spectroscopic, thermal and XRD characterization of hydroxyapatite from new natural sources", Spectrochimica Acta Part A: Molecular and Biomolecular Spectroscopy83(1), (2011),56-60. http://dx.doi.org/10.1016/j.saa.2011.07.036

[16] Shaltout A A, (private communications).

[17] Oyewale A O, Funtua I I, Ekwumemgbo P,"Energy dispersive x-ray fluorescence spectrometry analysis of elements in tobacco cigarette and ashed-tobacco samples", Journal of scientific \&industrial research, 61, (2002), 48-52. DOI: none

[18] Saadawi R, Figueroa J L, Hanleya T, Caruso J,"The hookah series part 1: total metal analysis in hookah Tobacco (narghile, shisha) - an initial study", Anal. Methods 4, (2012), 3604-3611. DOI: 10.1039/C2AY26065D

[19] Ryan J, Clark M,"Trace metal determination in Tobacco and cigarette ash by inductively coupled plasma-atomic emission spectroscopy", Concordia College Journal of Analytical $\quad$ Chemistry $\quad 1, \quad 34-41$. http://www.cord.edu/dept/chemistry/CCJAC/2010_Vol_1/2010_1_34.pdf.

[20] Tso T C,"Micro- and secondary-elements in tobacco", Agricultural Research Service Crop Research Division Usda, U.S. Dept of Agriculture; (1965). http://legacy.library.ucsf.edu/tid/mhs46e00

[21] Tso T C, Hallden N A, Alexander L T, "Radium-226 and polonium-210 in leaf Tobacco and Tobaccosoil", Science146 (3647), (1964), 10431045. PMID: 14202456

[22] Tso T C, Harley N, Alexander L T, "Source of lead-210 and polonium-210 in tobacco", Science 153(3738), (1966), 880-882. PMID: 5914751.

[23] Khater a M,"Polonium-210 budget in cigarettes،" Journal of Environmental Radioactivity 71, (2004), 33-41. DOI: 10.1016/S0265931X(03)00118-8

[24] Winters T H, Franza J R, "Radioactivity in Cigarette Smoke",New England Journal of Medicine 306(6),364-365(1982). http://www.rmeswi.com/36.html

[25] Ponte L,"Radioactivity: The New-Found Danger in Cigarettes", Reader's Digest, (1986), 123-127. http://www.acsa2000.net/HealthAlert/radioactive_tobacco.html.

[26] Kilthau G F,"Cancer risk in relation to radioactivity in tobacco", Radiologic Technology, 67(1996). http://www acsa2000 net/HealthAlert/radioactive tobacco.html.

[27] Yuille C L, Berke H L, Hull T,"Lung cancer following Pb210 inhalation in rats", Radiation Res.31, (1967), 760-774.

[28] Cohen B L,"Cancer Risk from Low-Level Radiation", American Journal of Roentgenology 179(5), (2002). http://www.ajronline.org/doi/full/10.2214/ajr.179.5.1791137.

[29] Shousha H A, Ahmad F, "Natural radioactivity contents in Tobacco and radiation dose induced from smoking", Radiation Protection Dosimetry 150(1): (2012), 91-95. DOI: 10.1093/rpd/ncr375

[30] Gorsky M, Epstein J B, Levi H, Yarom N,"Oral White Lesions Associated with Chewing Catha edulis",Tobacco Induced Diseases; 2, (2004),145-150. DOI:10.1186/1617-9625-2-3-145

[31] Yarom N, Levi J E, Porat D, Kaufman E,"Oral manifestations of habitual Cathaedulis chewing: a case-control study", Oral Radiology109 (6): (2010), e60-e66. http://dx.doi.org/10.1016/j.tripleo.2010.02.022.

[32] AL-Jalali M A, and Shaltout A A, Natural Radioactivity inspection of Catha edulis (Khat) and Tobacco plants collected from Yemen. International Journal of Innovative Research in Science and Engineering, Volume 2 issue 5, (2014), 350-354. http://ijirse.in/docs/May14/IJIRSE140511.pdf. 